\title{
A finite element analysis of sacroiliac joint displacements and ligament strains in response to three manipulations
}

\author{
Zhun $\mathrm{Xu}^{1,2}$, Yikai Li ${ }^{1 *}$, Shaoqun Zhang ${ }^{1,3}$, Liqing Liao ${ }^{1}$, Kai Wu' ${ }^{1}$ Ziyu Feng ${ }^{1}$ and Dan $\mathrm{Li}^{1}$
}

\begin{abstract}
Background: Clinical studies have found that manipulations have a good clinical effect on sacroiliac joint (SIJ) pain without specific causes. However, the specific mechanisms underlying the effect of manipulations are still unclear. The purpose of this study was to investigate the effects of three common manipulations on the stresses and displacements of the normal SIJ and the strains of the surrounding ligaments.

Methods: A three-dimensional finite element model of the pelvis-femur was developed. The manipulations of hip and knee flexion (MHKF), oblique pulling (MOP), and lower limb hyperextension (MLLH) were simulated. The stresses and displacements of the SIJ and the strains of the surrounding ligaments were analyzed during the three manipulations.

Results: MOP produced the highest stress on the left SIJ, at 6.6 MPa, while MHKF produced the lowest stress on the right SIJ, at $1.5 \mathrm{MPa}$. The displacements of the SIJ were all less than $1 \mathrm{~mm}$ during the three manipulations. The three manipulations caused different degrees of ligament strain around the SIJ, and MOP produced the greatest straining of the ligaments.

Conclusion: The three manipulations all produced small displacements of the SIJ and different degrees of ligament strains, which might be the mechanism through which they relieve SIJ pain. MOP produced the largest displacement and the greatest ligament strains.
\end{abstract}

Keywords: Manipulation, Sacroiliac joint, Displacement, Ligament strain, Finite element analysis

\section{Background}

The sacroiliac joint (SIJ) is the largest axial joint in the human body; it connects the spine and the lower limbs and transmits the weight of the upper body to the pelvis and lower limbs [1-3]. The SIJ is composed of an anterior synovial part and a tightly connected ligament part at the rear $[4,5]$. The sacrum is wedge-shaped, tilted from top to bottom and with a concave surface that is closely inserted into the convex surface of the ilium $[6,7]$. It

\footnotetext{
*Correspondence: lyk_doc@163.com

'School of Traditional Chinese Medicine, Southern Medical University, No.

1838, Guangzhou Avenue North, BaiYun District, Guangzhou 510515, Guangdong Province, China

Full list of author information is available at the end of the article
}

includes some strong intrinsic and extrinsic ligaments $[8,9]$. Due to its special anatomical structure, the SIJ is very stable [10-12]. However, certain bone or soft tissue lesions can cause joint instability, which subsequently induces SIJ pain. Recent studies have found that SIJ diseases can also cause low back pain and account for approximately $14.5-22.5 \%$ of cases [13].

The causes of SIJ pain include pathological bone destruction, traumatic fracture and dislocation, and pain without specific causes [5]. Commonly, abnormal gait, heavy physical exertion, leg length discrepancy, inflammation, scoliosis, and lumbar fusion surgery with fixation of the sacrum may be factors related to SIJ pain

(c) The Author(s). 2020 Open Access This article is licensed under a Creative Commons Attribution 4.0 International License, which permits use, sharing, adaptation, distribution and reproduction in any medium or format, as long as you give appropriate credit to the original author(s) and the source, provide a link to the Creative Commons licence, and indicate if changes were made. The images or other third party material in this article are included in the article's Creative Commons licence, unless indicated otherwise in a credit line to the material. If material is not included in the article's Creative Commons licence and your intended use is not permitted by statutory regulation or exceeds the permitted use, you will need to obtain permission directly from the copyright holder. To view a copy of this licence, visit http://creativecommons.org/licenses/by/4.0/ The Creative Commons Public Domain Dedication waiver (http://creativecommons.org/publicdomain/zero/1.0/) applies to the data made available in this article, unless otherwise stated in a credit line to the data. 
without specific causes [14]. The mechanism may include the following processes: Pathogenic factors acting on the auricular surface of the sacrum and ilium may cause injury to the ligaments or muscles around the SIJ, which will result in slight movement of the SIJ, making the joints difficult to reset. The mechanical environment of the joints may ultimately be imbalanced, and the soft tissues will be damaged. This condition is clinically referred to as SIJ subluxation [4]. Pathological bone destruction and traumatic fracture and dislocation require surgery [15-18], while SIJ pain without a specific cause is usually treated with manipulations $[19,20]$.

There are several common manipulations, including manipulation of hip and knee flexion (MHKF), manipulation of oblique pulling (MOP), and manipulation of lower limb hyperextension (MLLH). A large number of studies have reported that manipulations have a good effect on the treatment of SIJ subluxation [19-21]. Different types of SIJ subluxation require different manipulations [22, 23]. Some authors have suggested that the manipulations reduce pain by pulling the subluxated SIJ back into place [23-25]. Others have suggested that the SIJ is very stable and that the pain relief is the result of relieving the spasms of the ligaments and muscles around the SIJ [26, 27]. However, the mechanisms underlying the effect of manipulations on SIJ subluxation are not clear at present. Is it possible to pull the subluxated SIJ back into place with manipulations? Can manipulations cause ligament strain around the joints? None of these issues have been studied. In this study, the normal pelvic-femur finite element model is used to investigate the specific mechanisms underlying the effects of the three manipulations on the SIJ and its surrounding ligaments.

\section{Methods}

\section{Model construction}

A 3D finite element model of the SIJ was developed. Three-dimensional models of the sacrum, ilia and femurs were reconstructed from the computed tomography (CT) images of a healthy male volunteer (34 years old, $170 \mathrm{~cm}$ in height, and $65 \mathrm{~kg}$ in weight) using Mimics 20.0 (Materialise Company, Leuven, Belgium), and the cortical and cancellous regions of the bones were distinguished. Axial slices $0.5-\mathrm{mm}$ thick spanning the entire pelvis were selected for model construction. All surface models were meshed using Geomagic 2013 (Raindrop Company, Marble Hill, USA). The SIJ is composed of cartilage and the end-plate of the sacrum and the ilia, with their surrounding ligaments. The cartilage was reconstructed with a uniform thickness; the regions of the articular surfaces were based on CT images, and the thicknesses of the cartilage were acquired from the literature. The sacral and iliac cartilages had thicknesses of $2 \mathrm{~mm}$ and $1 \mathrm{~mm}$, respectively. The bone end-plate thicknesses of the sacral and iliac parts of the cartilage were assumed to be $0.23 \mathrm{~mm}$ and $0.36 \mathrm{~mm}$, respectively. The gap between the two cartilages was set at $0.3 \mathrm{~mm}$ [12]. The material properties chosen from previous studies $[12,28]$ are summarized in Table 1.

The anterior sacroiliac ligament (ASL), long posterior sacroiliac ligament (LPSL), short posterior sacroiliac ligament (SPSL), interosseous sacroiliac ligament (ISL), sacrospinous ligament (SS), and sacrotuberous ligament (ST) complexes were modelled as 3D tension-only truss elements. The attachment regions were chosen according to the literature [12]. Two fresh cadaver dissections were used to observe the ligaments' positions and orientations. The ASL was made up of numerous thin bands that spanned the ventral surface of the SIJ, connecting the lateral aspect of the sacrum to the margin of the auricular surface of the ilium. The LPSL extended from the posterior superior iliac spine to the third and fourth transverse tubercles of the back of the sacrum. The SPSL lay deep to the LPSL and consisted of large fibres attaching the lateral aspect of the dorsal sacral surface to the tuberosity of the ilium. The ISL lay in the intra-articular space and was composed of a series of short, strong fibres connecting the tuberosities of the sacrum and ilium. The SS was a thin triangular ligament that connected the ischial spine to the lateral border of the sacrum. The ST was behind the sacrospinous ligament, which attached the ischial tuberosity to the lateral border of the sacrum. The material properties of each ligament were obtained from the literature [28]. In total, the pelvic-femur model contained 727,474 elements and 275,399 nodes. Figure 1 shows the intact model with ligamentous attachments.

Three common manipulations were selected based on their popularity and validity. The point and orientation of the applied forces were determined by previous studies $[29,30]$. In addition, the magnitudes of the forces were determined by determining the manipulative power of five therapists using a biomechanical testing machine. The detailed loading and boundary conditions, as well as the $\mathrm{x}$-, $y_{-}$, and $\mathrm{z}$-axes, are described in Fig. 2. The compressive stresses and displacements of the SIJ and the ligament strains for the three manipulations were then investigated using Abaqus 2018 (Dassault Systemes S. A Company, Massachusetts, USA).

\section{Manipulation of hip and knee flexion}

The patient lay supine while the therapist flexed the patient's hip and knee as much as possible with pronation. Then, the therapist pushed down the knee, at which point the left hip joint was assumed to be fully constrained. The most posterior regions of the sacrum and the posterior superior iliac spine were fixed. The left hip was flexed to $155^{\circ}$ and was intorted to $35^{\circ}$. A compressive (downward) force of $600 \mathrm{~N}$ along the ventral-dorsal 
Table 1 Material properties of the sacrum, ilium, femur, pubic symphysis and endplate

\begin{tabular}{llll}
\hline & & Young's modulus (MPa) & Poisson's ratio \\
\hline Sacrum & Cortical & 12,000 & 0.3 \\
& Cancellous & 100 & 0.2 \\
Ilium & Cortical & 12,000 & 0.3 \\
& Cancellous & 100 & 0.2 \\
Femur & Cortical & 15,000 & 0.3 \\
& Cancellous & 100 & 0.2 \\
Pubic symphysis & & 5 & 0.45 \\
Articular cartilage & & 100 & 0.3 \\
Endplate & & 1000 & 0.4 \\
\hline
\end{tabular}

direction was simultaneously applied at the end of the left femur.

\section{Manipulation of oblique pulling}

The patient was in the side-lying position, and the therapist stood at the patient's ventral side. The therapist placed one hand on the dorsal side of the sacrum to fix the patient's position and placed the other hand on the anterior superior spine, pushing the ilium towards the back. Thus, most regions of the sacrum and the right iliac crest were fixed. Then, a push force of $600 \mathrm{~N}$ along the ventral-dorsal direction and parallel to the left SIJ surface was applied to the left anterior superior spine.

\section{Manipulation of lower limb hyperextension}

The patient lay in a prone position, and the leg being treated was hyperextended at the hip so that the anterior superior spine could just lift off the bed. Then, the therapist applied a downward force to the iliac crest being treated. In this manner, the right lateral region of the ilium and the right pubic tubercle were fixed. Then, a push force of $600 \mathrm{~N}$ along the dorsal-ventral direction and parallel to the left SIJ surface was applied on the left iliac crest. The point of the applied force was the midpoint between the highest point of the iliac crest and the posterior superior spine.

\section{Mesh convergence study}

To evaluate the degree of accuracy of our FE model, a detailed mesh convergence study was conducted. Four FE models were developed. The number of elements and nodes for each mesh resolution is shown in Table 2 . The meshes shown in Fig. 3 were named as mesh 1, mesh 2, mesh 3 and mesh 4, respectively. Following boundary conditions and material properties, loads, and constraints described in detail in the above sections, MHKF, MOP and MLLH were applied to these meshes. The results of the maximum stress and maximum displacement were numerically estimated for each of the meshes.

\section{Model validation}

To validate the developed models, two tests were performed. For the pelvic model, the distribution of the principal strain of the pelvis was compared with that

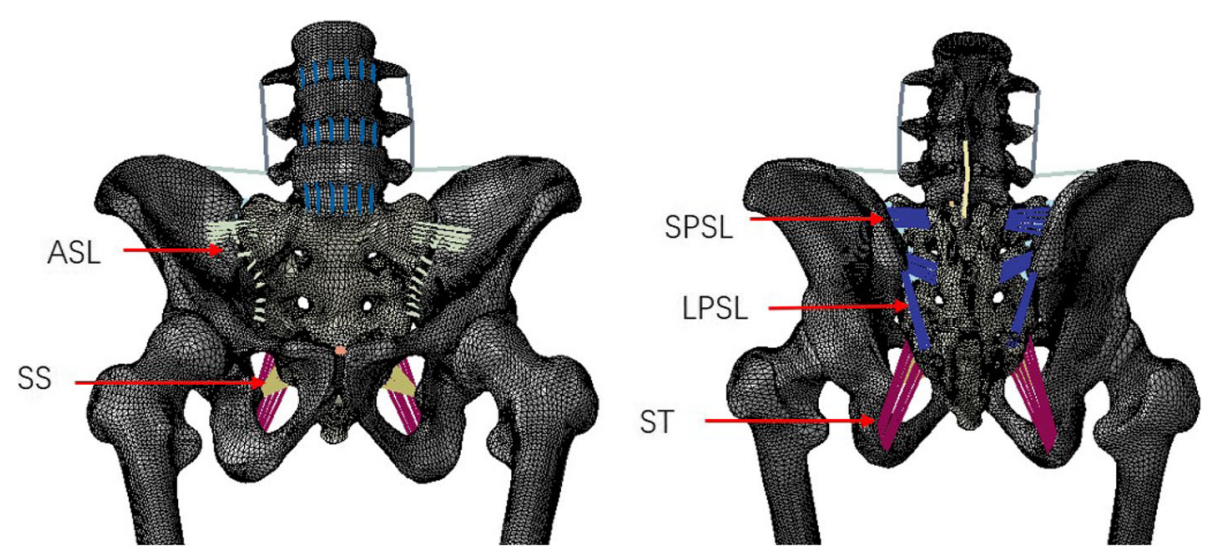

Fig. 1 Ventral (left) and Dorsal (right) views of the finite element model. Ligaments are represented in color lines, with red arrows identifying each ligament complex (note the interosseous sacroiliac ligament is not visible in anterior-posterior views). ASL indicates anterior sacroiliac ligament; LPSL, long posterior sacroiliac ligament; SPSL, short posterior sacroiliac ligament; SS, sacrospinous ligament; ST, sacrotuberous ligament 


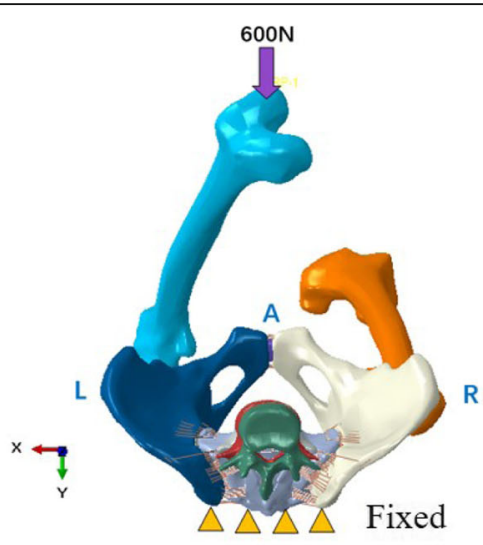

a

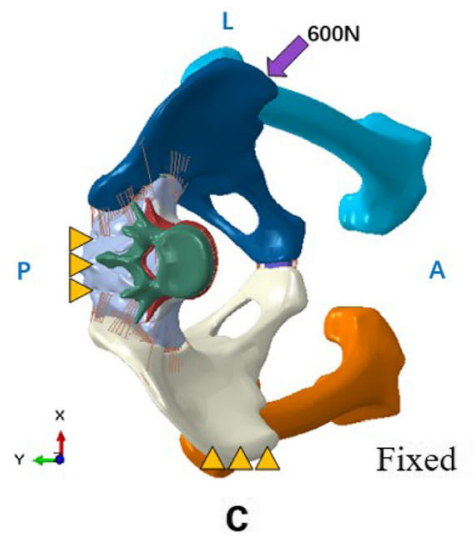

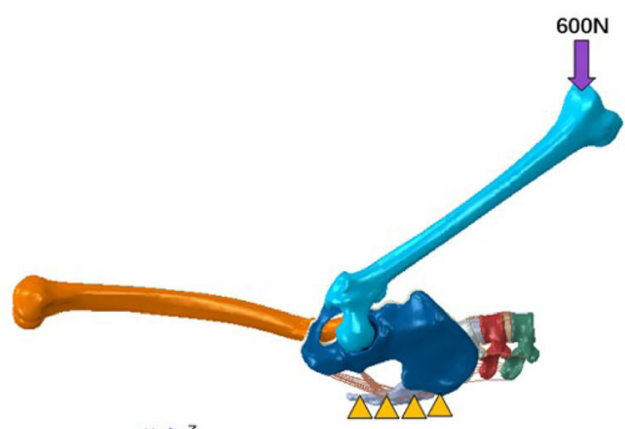

Fixed

b

$\mathrm{L}$

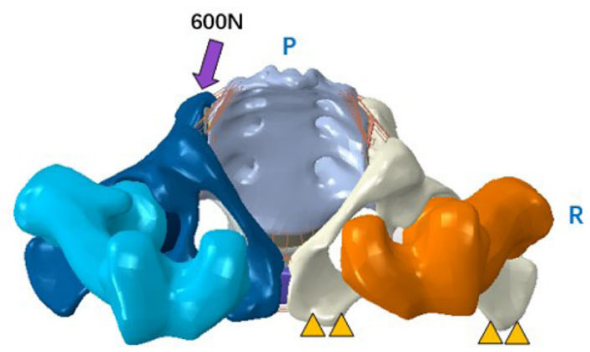

Fixed

d

Fig. 2 Loading and boundary conditions for the three manipulations. a The manipulation of hip and knee flexion (axial view); $\mathbf{b}$ The manipulation of hip and knee flexion (lateral view); c The manipulation of oblique pulling; $\mathbf{d}$ The manipulation of lower limb hyperextension

indicated in the study of Zhang [31]. Zhang et al. analyzed the distribution of principal strain on the cortical bone of the pelvis for the single-legged stance. In this model, the distribution of the principal strain of the pelvis was investigated under the same loading and boundary conditions.

For the sacrum model, the relationship between load and displacement was compared to that reported in cadaveric [32] and computational studies [12,33]. In the cadaveric experiment, the bilateral ilia were fixed. Five translational forces (anterior, posterior, superior, inferior, and mediolateral) of $294 \mathrm{~N}$ and three moments (flexion,

Table 2 Element and node numbers for four different mesh resolutions

\begin{tabular}{lll}
\hline & Element number & Node number \\
\hline Mesh 1 & 204,097 & 80,010 \\
Mesh 2 & 378,211 & 140,844 \\
Mesh 3 & 727,474 & 275,399 \\
Mesh 4 & $1,603,938$ & 669,044 \\
\hline
\end{tabular}

extension, and axial rotation) of $42 \mathrm{Nm}$ were applied separately to the centre of the sacrum. The displacements of a node lying in the mid-sagittal plane between the inferior S1 and superior S2 vertebral endplates were calculated. In this model, the displacement was estimated under the same loading.

\section{Results}

\section{Mesh convergence study}

The results of the maximum stress and maximum displacement on the left SIJ surface of sacrum were investigated for each of the meshes, for MHKF, MOP and MLLH, which can be seen in Fig. 4. The differences in maximum stress and maximum displacement between mesh 3 and mesh 4 in all three manipulations were less than $5 \%$, which was concluded as reasonably close ranges. Based on this finding, mesh 3 with 727,474 elements was selected for further study.

\section{Model validation}

The principal stresses were distributed mainly in the upper and posterior areas of the acetabulum and 


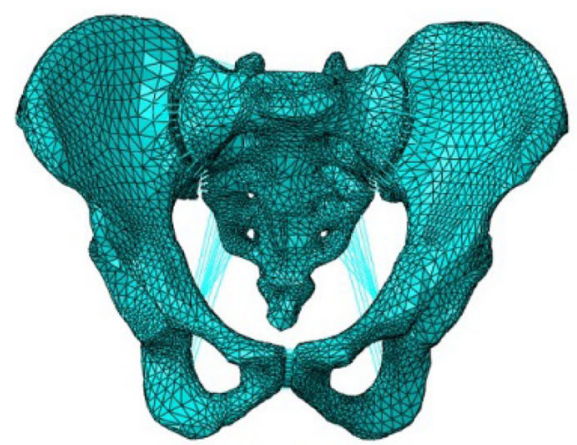

Mesh 1

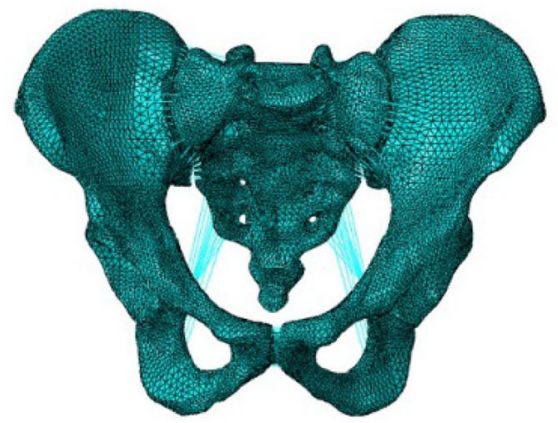

Mesh 3

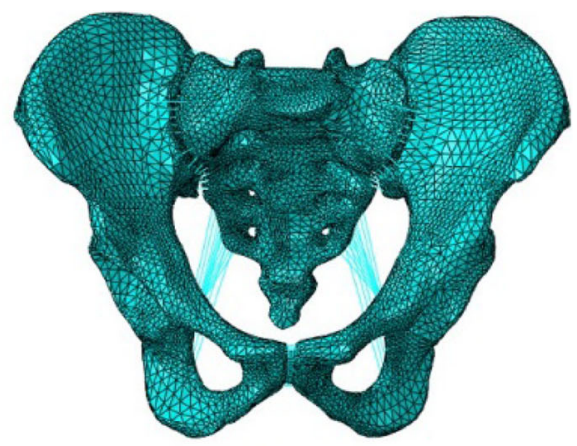

Mesh 2

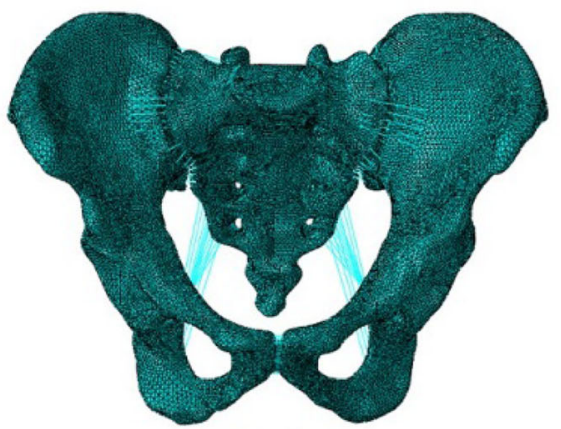

Mesh 4

Fig. 3 Four meshes for mesh convergence study

extended to the iliac crest, the incisura ischiadica major, and the rear acetabulum. The distribution and maximum value of stress were consistent with those reported in a previous study [31]. Figure 5 shows that the displacements under eight loading conditions were in agreement not only with those in an experimental study but also with those in some computational studies [12, 32, 33].

The distribution of compressive stresses on the SIJ surface of the sacrum is shown in Fig. 6. Higher stress was observed on the left SIJ for the three manipulations. Among them, MOP could produce the highest stress on the left SIJ, at $6.6 \mathrm{MPa}$, while MHKF could produce the lowest stress on the right SIJ, at $1.5 \mathrm{MPa}$.

In MHKF, the displacements of the left SIJ were 0.120, 0.033 , and $0.043 \mathrm{~mm}$ in the superior-inferior (SI), anterior-posterior (AP), and medial-lateral (MI) directions, respectively. In MOP, the displacements were 0.048, 0.962, and $0.117 \mathrm{~mm}$ in the SI, AP, and MI directions, respectively. In MLLH, the displacements were $0.013,0.114$, and $0.060 \mathrm{~mm}$ in the SI, AP, and MI directions, respectively. MOP produced the largest displacement in the AP and MI directions, while MHKF

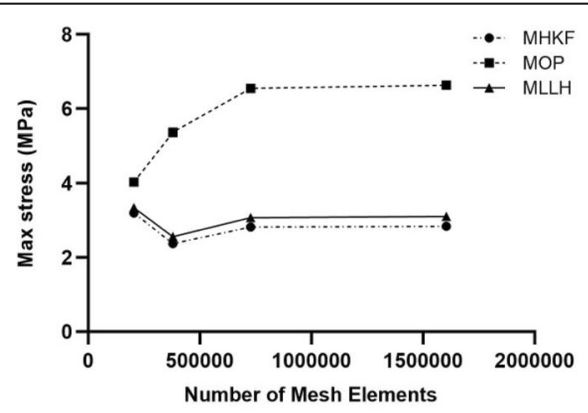

a

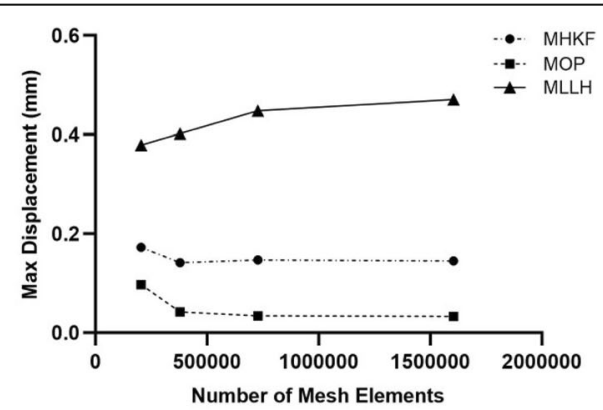

b

Fig. 4 a Maximum stress on the left SIJ surface of sacrum for different number of mesh elements, for MHKF, MOP and MLLH. b Maximum displacement on the left SIJ surface of sacrum for different number of mesh elements, for MHKF, MOP and MLLH 


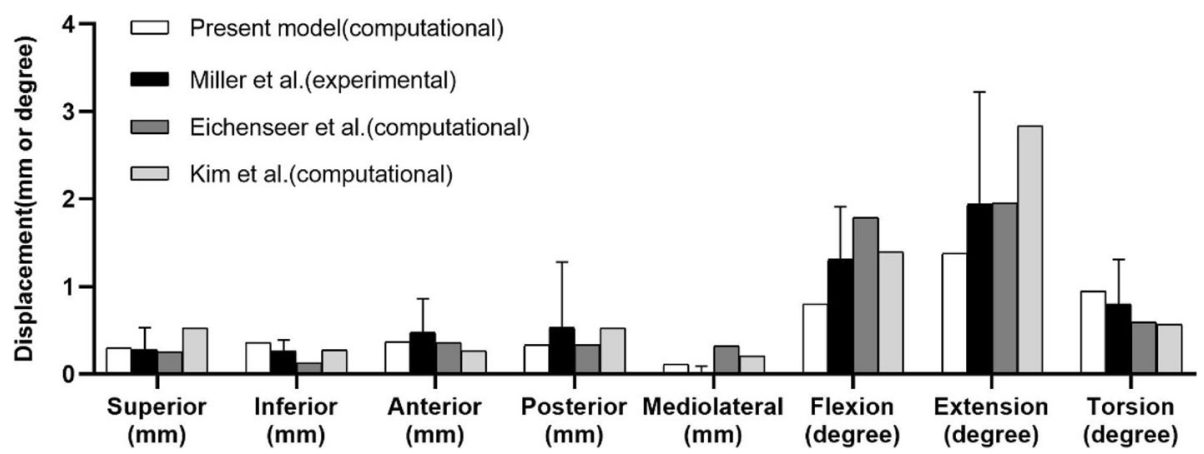

Fig. 5 Comparison of sacral displacements under eight loadings comparable to those in previous experimental and computational studies

produced the largest displacement in the SI direction. The displacements of the left SIJ are shown in Fig. 7.

The strains of six ligaments for the three manipulations are shown in Fig. 8. For most of the ligaments, the strain of the left ligament was greater than that of the right ligament under the three manipulations. In MHKF, the left SS, ASL and ST had the highest strain values, which were $1.6,1.1$ and $0.7 \%$, respectively. MLLH produced the lowest strains of ligaments, while MOP produced the highest strains of ligaments. The left ISL and LPSL had the highest strain values $(0.8$ and $0.3 \%$, respectively) in MLLH. In MOP, the left SS, ASL, and ST had the greatest strain values, which were $3.1,1.6$, and $1.1 \%$, respectively.

\section{Discussion}

SIJ pain is a common disease that affects $90 \%$ of adults throughout their lives [2]. Manipulations have a good effect on SIJ pain with no specific cause. However, the mechanism underlying the effects of manipulations on the SIJ and the ligaments are not yet clear. In this study, a 3D finite element model was used to quantitatively analyze the effects of three manipulations on the displacements of the SIJ and the strains of surrounding ligaments, thus providing a theoretical basis for the indications for manipulations.

In this study, we found that higher stress was observed on the left SIJ, which may be related to the manipulative force applied to the left SIJ. MOP applied force to the iliac directly, and MHKF applied force to the femur indirectly. Therefore, MOP produced the maximum force on the left SIJ, and MHKF produced the minimum force on the right SIJ.

The anterior part of the SIJ is the synovium, which can move slightly, and the posterior part is the interosseous ligament, which mainly plays a role in maintaining the stability of the joint. Walker et al. [34] found that the SIJ had a displacement range of motion of less than $3 \mathrm{~mm}$ and a rotation of no more than $2^{\circ}$ in a standing or sitting position. Some researchers found that the slip of the SIJ did not even exceed $1 \mathrm{~mm}$ [35]. In this study, it was found that MOP could produce the maximum displacement of the SIJ among the three manipulations, with a value of $0.962 \mathrm{~mm}$, while MLLH could cause the minimum displacement of the SIJ, with a value of 0.114 $\mathrm{mm}$. The displacements of the SIJ under the three manipulations were all less than $1 \mathrm{~mm}$, which is consistent with previous studies [34, 35].

In MLLH, both the sacrum and iliac bone were unfixed directly. As a result, they moved simultaneously during the process. Therefore, the relative displacement of the joint surface was small. The displacement produced by MHKF was also small, which might be related to the point of force at the distal femur. The displacement produced by MOP was the largest, considering that the point of force was on the pelvis, and the direction of force was medial-lateral. MOP produced the largest displacement in the AP and MI directions, and MHKF produced the largest displacement in the SI direction. The biomechanical properties of manipulations can provide a theoretical basis for selecting a manual therapy technique.

Ligaments play an important role in maintaining the stability of the pelvis. Sichting et al. [36] found that ligaments serve as the mechanical stabilization device of the pelvis. Bohme et al. [37] observed that the ASL and ST had the greatest load, with 80 and $17 \%$ of the total load, respectively, in anteroposterior compression pelvic injuries and that the SS played an important role in the vertical stability of the pelvis. Eichenseer et al. [33] suggested that the ligaments around the SIJ could limit its movement and reduce its stress. This study found that the three manipulations could cause different degrees of strain on the ligaments around the SIJ. In MOP, the patient's sacrum was relatively fixed, the point of force was on the anterior superior iliac spine, and the force was in the MI direction. Therefore, MOP caused the greatest strain on the ligaments among the three manipulations. The ligament strains produced by MLLH and MHKF were smaller, a finding that might be related to the point and direction of manipulative force as well as the style 


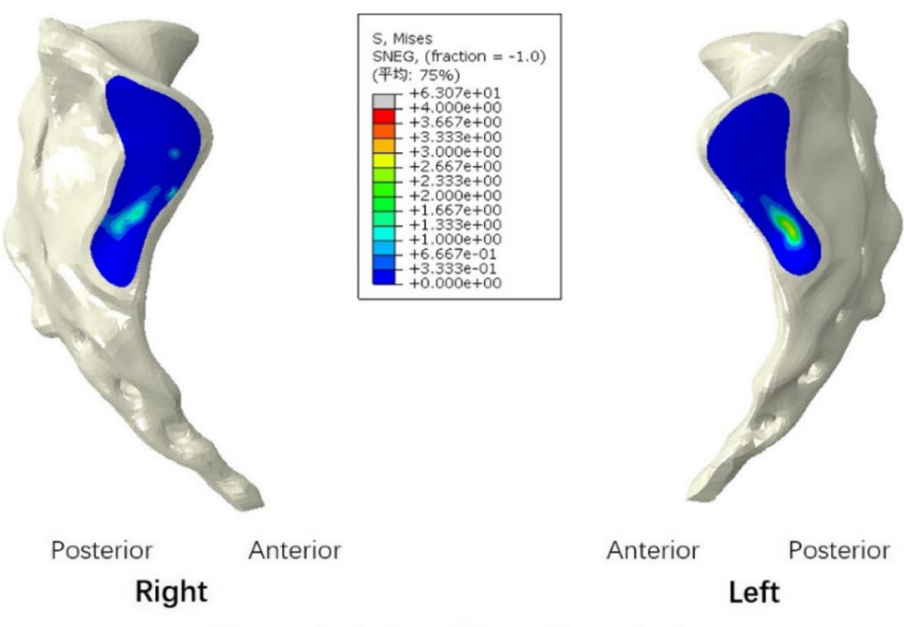

The manipulation of hip and knee flexion

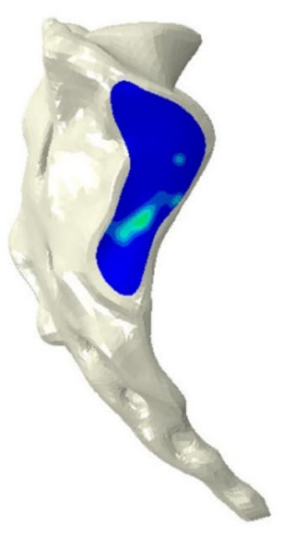

Posterior Right

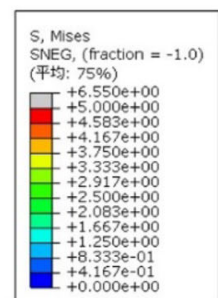

Anterior

$+0.000 e+00$

The manipulation of oblique pulling

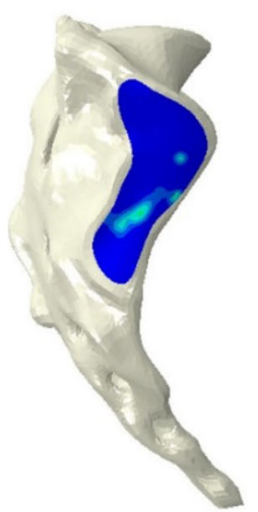

Posterior

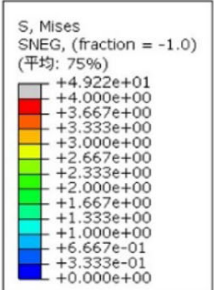

Right

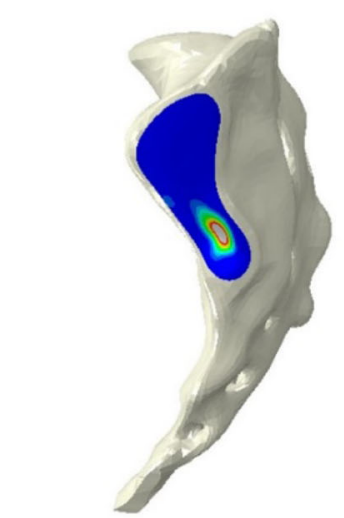

Anterior Posterior Left

The manipulation of lower limb hyperextension

Fig. 6 Distribution of compressive stresses on the SIJ surface of sacrum for the three manipulations 


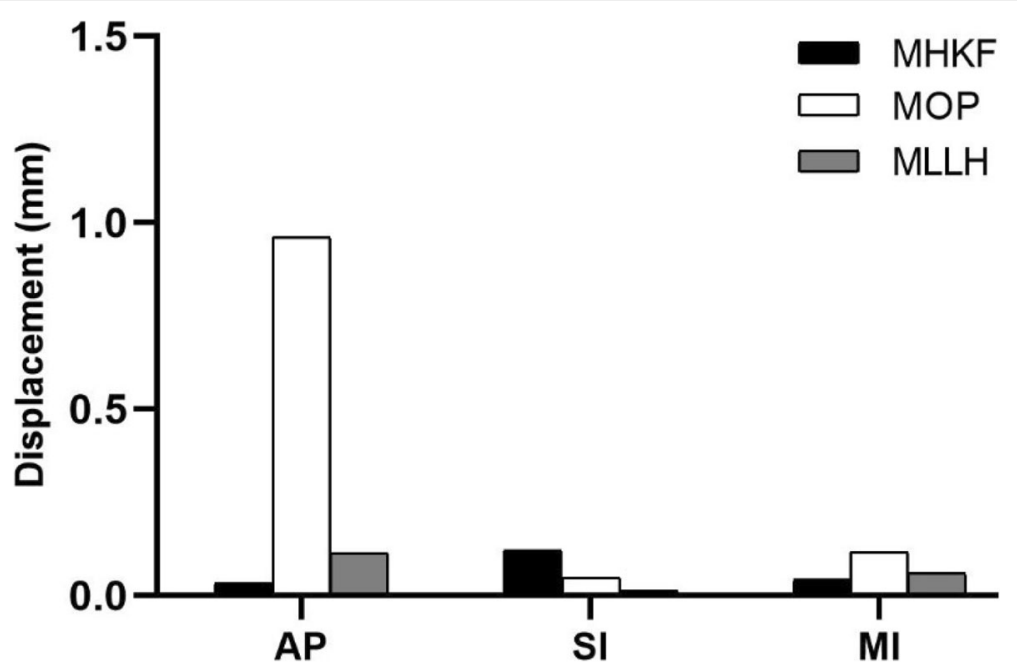

Fig. 7 The left sacroiliac joint displacements for the three manipulations. MHKF: The manipulation of hip and knee flexion; MOP: The manipulation of oblique pulling; MLLH: The manipulation of lower limb hyperextension. AP: Anterior-posterior direction; SI: Superior-inferior direction; MI: Medial-lateral direction

of pelvic fixation. These results indicate that SS, ASL and ISL experienced the greatest strain under the three manipulations, which was consistent with previous studies [12, 33].

In MLLH, the displacements were the smallest, and the ligament strains were also the smallest. In MOP, the displacements and the ligament strains were both the largest. The displacements of SIJ and the ligament strains remain consistent under the three manipulations. These results also prove the reliability and effectiveness of the model. According to these results, it can be found that MOP is the manipulation that causes the greatest changes in the environment around the SIJ. These results were based on the condition that the manipulations acted on the normal SIJs. However, manipulations were applied on the patients with SIJ subluxation, so these results may have certain errors. In theory, if manipulations can produce the displacement of normal SIJ or the ligament strain, it can also lead to the movement of subluxated SIJ or the change of ligament strain.

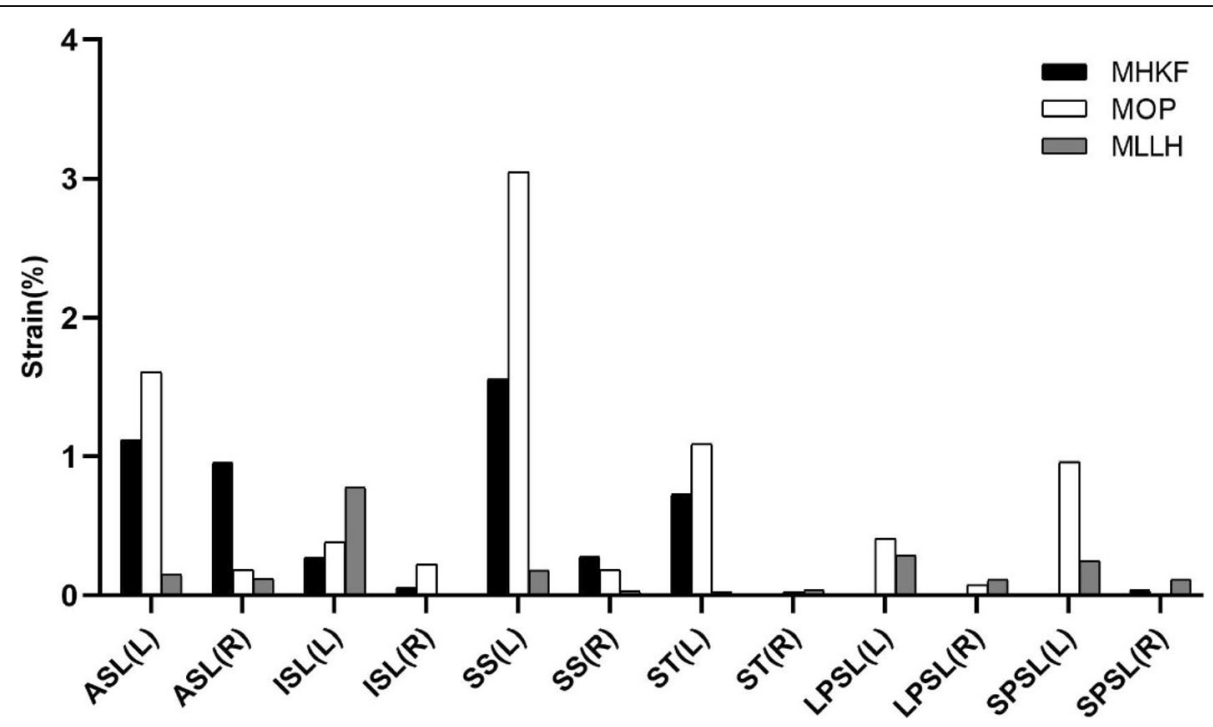

Fig. 8 Ligament strains for the three manipulations. MHKF: The manipulation of hip and knee flexion; MOP: The manipulation of oblique pulling; MLLH: The manipulation of lower limb hyperextension; L: Left; R: Right; ASL: Anterior sacroiliac ligament; ISL: Interosseous sacroiliac ligament; SS: Sacrospinous ligament; ST: Sacrotuberous ligament; LPSL: long posterior sacroiliac ligament; SPSL: Short posterior sacroiliac ligament 
Szadek et al. [38] found that there were substance P and calcitonin gene-related peptide-positive nerve fibres in the SIJ cartilage and surrounding ligaments, indicating that the source of SIJ pain might be cartilage and ligament tissues. Is it then possible to reduce pain by pulling the subluxated SIJ back or by alleviating spasms of the surrounding ligaments? Chen et al. [39] suggested that manipulations are unlikely to pull the SIJ back. The clicking sound and the sense of movement during the manipulative process are likely due to movement of attachment of the SIJ or L5/S1 facet joints. Tullberg et al. [26] argued that manipulations cannot change the position of the SIJ and that the pain relief was related to changes in the soft tissues around the joints. Ivanov et al. [40] also suggested that the ligaments around the SIJ contained a considerable amount of nerve tissue and that even a small strain would cause pain. Based on the results of this study, the displacements of the SIJ were less than $1 \mathrm{~mm}$ for all three manipulations. In fact, because there are many muscles and other soft tissues around the SIJ in the human body, it can be assumed that any displacement will be small and that it is difficult to pull the SIJ back with manipulations. However, the manipulations did cause different degrees of strain on the surrounding ligaments. Although the degree of ligament strain was small, it could still relieve the spasm of the surrounding ligaments and reduce pain.

There are some limitations of this study. First, our finite element model is based on the geometric and material properties of individual pelvic bones and ligaments in a single male case. However, it is well known that the anatomical structures of the pelvis differ greatly among individuals. This factor must be considered when drawing conclusions in clinical studies. Second, muscles and other soft tissues are most likely to participate in maintaining pelvic stability, and manipulative forces were applied on soft tissues, not directly on bony structures. These factors with muscles and soft tissues were not considered in this model. Third, the ligaments' characteristics are regarded as linear. Fourth, there is currently no unified standard for manipulations. Therefore, the specific processes of manipulations were simulated and simplified based on the experience of many physicians. Fifth, manipulations are used to treat SIJ subluxation, but the mechanisms of manipulations were investigated with normal SIJ in this study. Therefore, these results may not fully reflect the effect of manipulations. The model of SIJ subluxation and ligament spasm is difficult to establish, and we also plan to do further research in the future.

\section{Conclusions}

This study was the first to analyze the effects of three manipulations on the stresses and displacements of the
SIJ and the strains of the surrounding ligaments. The results showed that the displacements of the SIJ produced by the three manipulations were small, but the three manipulations could produce different degrees of ligament strains, which might explain how the manipulations relieve SIJ pain. MOP produced the largest displacement and the greatest ligament strains.

\section{Abbreviations \\ SIJ: Sacroiliac joint; MHKF: The manipulation of hip and knee flexion; MOP: The manipulation of oblique pulling; MLLH: The manipulation of lower limb hyperextension; ASL: Anterior sacroiliac ligament; ISL: Interosseous sacroiliac ligament; SS: Sacrospinous ligament; ST: Sacrotuberous ligament; LPSL: Long posterior sacroiliac ligament; SPSL: Short posterior sacroiliac ligament; AP: Anterior-posterior direction; SI: Superior-inferior direction; Ml: Medial-lateral direction}

\section{Acknowledgements}

Not applicable.

\section{Authors' contributions}

ZX and SQZ carried out the finite element analysis and drafted the manuscript. YKL, LQL and KW participated in the study design and discussion of the clinical results. ZYF and DL constructed the finite element models, performed the biomechanical analysis. All of the authors read and approved the final manuscript.

\section{Funding}

This work was supported by the National Natural Science Foundation of China (grant number 81674095). The funder mainly undertaken the design of the study and the analysis of the results, and was the corresponding author in this study.

\section{Availability of data and materials}

The datasets used and/or analyzed during the current study are available from the corresponding author upon reasonable request.

\section{Ethics approval and consent to participate}

The study was approved by Ethics Committee of the First Affiliated Hospital of University of South China. Written informed consent was available, and participant involved gave his consent for the use of individual data and experimental data.

Consent for publication

Not applicable.

\section{Competing interests}

The authors declare that they have no competing interests.

\section{Author details \\ ${ }^{1}$ School of Traditional Chinese Medicine, Southern Medical University, No. 1838, Guangzhou Avenue North, BaiYun District, Guangzhou 510515, Guangdong Province, China. ${ }^{2}$ Department of Spine Surgery, The First Affiliated Hospital of University of South China, Hengyang 421000, Hunan Province, China. ${ }^{3}$ ShenZhen Traditional Chinese Medicine Hospital, Shenzhen, Guangdong, PR China.}

Received: 6 June 2020 Accepted: 20 October 2020

Published online: 28 October 2020

References

1. Cohen SP. Sacroiliac joint pain: a comprehensive review of anatomy, diagnosis, and treatment. Anesth Analg. 2005;101(5):1440-53.

2. Joukar A, Shah A, Kiapour A, Vosoughi AS, Duhon B, Agarwal AK, et al. Sex specific sacroiliac ioint biomechanics during standing upright: a finite element study. Spine. 2018;43(18):e1053-e60.

3. Wu T, Ren X, Cui Y, Cheng X, Peng S, Hou Z, et al. Biomechanical study of three kinds of internal fixation for the treatment of sacroiliac joint disruption 
using biomechanical test and finite element analysis. J Orthop Surg Res. 2018;13(1):152.

4. Yang XW, Chen ZJ, Zhang SQ, Zhang MC, Li YK. A three-dimensional finite element analysis of sacroiliac joint exerted simulating oblique-pulling manipulation. J Pract Med. 2014;30(14):2228-30.

5. Al-Subahi M, Alayat M, Alshehri MA, Helal O, Alhasan H, Alalawi A, et al. The effectiveness of physiotherapy interventions for sacroiliac joint dysfunction: a systematic review. J Phys Ther Sci. 2017;29(9):1689-94.

6. Liang SH, Ye GH, Chen HL, Liu XH, Li YK. Clinical study of sacroiliac joint subluxation. Chin J Rehabil Med. 2007;22(2):172-3.

7. Shi D, Wang F, Wang D, Li X, Wang Q. 3-D finite element analysis of the influence of synovial condition in sacroiliac joint on the load transmission in human pelvic system. Med Eng Phys. 2014;36(6):745-53.

8. Rothkötter HJ, Berner W. Failure load and displacement of the human sacroiliac joint under in vitro loading. Arch Orthop Trauma Surg. 1988, 107(5):283-7.

9. Aihara T, Takahashi K, Yamagata M, Moriya H, Shimada Y. Does the iliolumbar ligament prevent anterior displacement of the fifth lumbar vertebra with defects of the pars? J Bone Joint Surg Br Vol. 2000;82(6):846-50.

10. Vleeming A, Van Wingerden JP, Dijkstra PF, Stoeckart R, Snijders CJ, Stijnen T. Mobility in the sacroiliac joints in the elderly: a kinematic and radiological study. Clin Biomechanics (Bristol, Avon). 1992;7(3):170-6.

11. Dujardin FH, Roussignol $\mathrm{X}$, Hossenbaccus M, Thomine JM. Experimental study of the sacroiliac joint micromotion in pelvic disruption. J Orthop Trauma. 2002;16(2):99-103.

12. Kim YH, Yao Z, Kim K, Park WM. Quantitative investigation of ligament strains during physical tests for sacroiliac joint pain using finite element analysis. Man Ther. 2014;19(3):235-41.

13. Lindsey DP, Perez-Orribo L, Rodriguez-Martinez N, Reyes PM, Newcomb A, Cable A, et al. Evaluation of a minimally invasive procedure for sacroiliac joint fusion-an in vitro biomechanical analysis of initial and cycled properties. Med Devices (Auckland, NZ). 2014;7:131-7.

14. Schuit D, McPoil TG, Mulesa P. Incidence of sacroiliac joint malalignment in leg length discrepancies. J Am Podiatr Med Assoc. 1989;79(8):380-3.

15. Cody JP, Kang DG, Lehman RA. Combat-related lumbopelvic dissociation treated with percutaneous sacroiliac screw placement. Spine J. 2012;12(9): 858-9.

16. Fu S, Zhao Y, Lian W, Zou D, Sun T, Zhao Y, et al. Comparison of the risk of breakage of two kinds of sacroiliac screws in the treatment of bilateral sacral fractures. Eur Spine J. 2014;23(7):1558-67.

17. Shui $X$, Ying $X$, Mao C, Feng Y, Chen L, Kong J, et al. Percutaneous screw fixation of crescent fracture-dislocation of the sacroiliac joint. Orthopedics. 2015;38(11):e976-82.

18. Zhou YJ, Yunus A, Tian Z, Chen JT, Wang C, Xu LL, et al. The pedicle screwrod system is an acceptable method of reconstructive surgery after resection of sacroiliac joint tumours. Contemporary Oncol (Poznan, Poland). 2016;20(1):73-9.

19. Cleland JA, Fritz JM, Kulig K, Davenport TE, Eberhart S, Magel J, et al. Comparison of the effectiveness of three manual physical therapy techniques in a subgroup of patients with low back pain who satisfy a clinical prediction rule. Spine. 2009;34(25):2720-9.

20. Nejati P, Safarcherati A, Karimi F. Effectiveness of exercise therapy and manipulation on sacroiliac joint dysfunction: a randomized controlled trial. Pain Phys. 2019;22(1):53-61.

21. Kamali F, Shokri E. The effect of two manipulative therapy techniques and their outcome in patients with sacroiliac joint syndrome. J Bodyw Mov Ther. 2012;16(1):29-35.

22. Luan L, Wen YK. Treatment of sacroiliac joint dislocation with bone setting manipulation. China J Orthop Traumatol. 2009;22(04):311-3.

23. Huang JN, He YF, Liu H, He ZT, Wu BJ, Zhao XY. Diagnosis, treatment and research advances of sacroiliac joint dislocation. Chin J Tissue Eng Res. 2019; 23(20):3201-6.

24. Fan CZ. The review of traumatic sacroiliac joint subluxation. Infromation Tradit Chin Med. 1984;02:39-41.

25. Liu JX, Huang $Y$, Zhang $H$, Chen $X$. Diagnosis and treatment of the subluxation of sacroiliac joint. J Cervicodynia Lumbodynia. 2000;02:118-20.

26. Tullberg T, Blomberg S, Branth B, Johnsson R. Manipulation does not alter the position of the sacroiliac joint. A roentgen stereophotogrammetric analysis. Spine. 1998;23(10):1124-8.
27. Wang $X C$, Xiao HE, Wang $X \mathrm{X}$. Three-step combined manipulation for the treatment of 132 cases of sacroiliac joint misalignment. Chin J Tradit Med Traumatol Orthop. 2011;19(06):40-1.

28. Lee $\mathrm{CH}$, Hsu CC, Huang PY. Biomechanical study of different fixation techniques for the treatment of sacroiliac joint injuries using finite element analyses and biomechanical tests. Comput Biol Med. 2017;87:250-7.

29. Xu F, Hou WL. Two kinds of therapeutic methods and effectiveness observation in acute sacroiliac joint injury. Chin J Tradit Med Traumatol Orthop. 2003;11(5):6-8.

30. Bao XR, Wang Q, Peng L, Yu J. Modified inclined pulling manipulation in treatment of disorders of sacroiliac joint. Chin Gen Prac. 2013;16(3):310-1.

31. Zhang QH, Wang JY, Lupton C, Heaton-Adegbile P, Guo ZX, Liu Q, et al. A subject-specific pelvic bone model and its application to cemented acetabular replacements. J Biomech. 2010;43(14):2722-7.

32. Miller JA, Schultz AB, Andersson GB. Load-displacement behavior of sacroiliac joints. J Orthop Res. 1987;5(1):92-101.

33. Eichenseer PH, Sybert DR, Cotton JR. A finite element analysis of sacroiliac joint ligaments in response to different loading conditions. Spine. 2011; 36(22):E1446-52.

34. Walker JM. The sacroiliac joint: a critical review. Phys Ther. 1992;72(12):903-16

35. Wilke HJ, Fischer K, Jeanneret B, Claes L, Magerl F. In vivo measurement of 3-dimensional movement of the iliosacral joint. Zeitschrift fur Orthopadie und ihre Grenzgebiete. 1997;135(6):550-6.

36. Sichting F, Rossol J, Soisson O, Klima S, Milani T, Hammer N. Pelvic belt effects on sacroiliac joint ligaments: a computational approach to understand therapeutic effects of pelvic belts. Pain Phys. 2014;17(1):43-51.

37. Bohme J, Lingslebe U, Steinke H, Werner M, Slowik V, Josten C, et al. The extent of ligament injury and its influence on pelvic stability following type II anteroposterior compression pelvic injuries-a computer study to gain insight into open book trauma. J Orthop Res. 2014;32(7):873-9.

38. Szadek KM, Hoogland PV, Zuurmond WW, De Lange JJ, Perez RS. Possible nociceptive structures in the sacroiliac joint cartilage: An immunohistochemical study. Clin Anatomy (New York, NY). 2010;23(2):192-8.

39. Chen ZJ, Yang XW, Xiang XB. 3D finite element analysis on pelvic under compressing manipulation by flexing hip and knee. J Med Biomechanics. 2015;30(3):233-7.

40. Ivanov AA, Kiapour A, Ebraheim NA, Goel V. Lumbar fusion leads to increases in angular motion and stress across sacroiliac joint: a finite element study. Spine. 2009;34(5):E162-9.

\section{Publisher's Note}

Springer Nature remains neutral with regard to jurisdictional claims in published maps and institutional affiliations.

Ready to submit your research? Choose BMC and benefit from:

- fast, convenient online submission

- thorough peer review by experienced researchers in your field

- rapid publication on acceptance

- support for research data, including large and complex data types

- gold Open Access which fosters wider collaboration and increased citations

- maximum visibility for your research: over $100 \mathrm{M}$ website views per year

At BMC, research is always in progress.

Learn more biomedcentral.com/submissions 